\title{
Analysis on the Master Plan of the Development and Utilization of Underground Space in Baoding City
}

\author{
Qian Wang ${ }^{a}$, Hongwei Li ${ }^{b}$ \\ College of urban and rural construction, Agricultural University of Hebei, Baoding, RP. China. \\ awangqianUP@yeah.net
}

\begin{abstract}
Keywords: Underground space,Development and utilization,Baoding city
Abstract. The development and utilization of urban underground space is an effective way to use the limited space more reasonably and economically which has great practical significance for expanding the urban space capacity and improving the quality of the city. This paper explores planning idea, overall layout, special planning and key regions on the basis of the master plan of development and utilization of underground space in Baoding City in the expectation that it could provide references and ideas for other large and medium-sized cities in the aspect of using underground space reasonably.
\end{abstract}

\section{Introduction}

Land resource is the most fundamental factor for the economic and social development and people's life. At present, China is facing crucial strategic opportunity of development. The contradiction between supply and demand of land resources is increasingly prominent. The development of urban underground space is one of the most effective measures to alleviate this contradiction and save construction land of city. As one of the important nodes of Jing-Jin-Ji District, Baoding edited the Master Plan of the Development and Utilization of Urban Underground Space in 2009, and effectively guided the development and utilization of underground space. The content of the plan is comprehensive, and the planning method is representative. This paper selected this plan of Baoding city as an example, discussed the method of underground space planning in large and intermediate cities, and provided directions for the planning establishment and development of underground space of other cities.

\section{Overview of Development and Utilization of Underground Space in Baoding City}

At present, the underground space in Baoding city includes facilities of underground transportation, public activity, civil air defense projects, storage, equipment, and so on so forth. The developed underground area is about 2.6 million square meters (end of 2009), including the parking area accounts for about 22\%, commercial area about 6\%, storage area about $67 \%$, and others about $5 \%$. Civil air defense facilities have 619 thousands square meters, accounting for about $24 \%$ of the total area. The development and utilization of Underground space is mainly shallow layer $(0 \sim-3 \mathrm{~m}, 0 \sim$ $-10 \mathrm{~m}$ ) based.

Overall, the current rate of utilization of underground space of Baoding is still low.At the same time, the method of utilization is simple; the planning and construction are under-developed and lack of management; the institution is to be improved. Therefore, it is urgent to make a comprehensive plan before practice the utilization of underground space.

\section{Planning Idea of Development and Utilization of Urban Underground Space in Baoding City}

Planning the function and layout of underground space reasonably; determine the plane layout form and the depth of the underground space; put forward the principles of planning and control; and coordinate the public space and other functional space. Efficiently and economically utilize the underground resources; promote the coordinated development of three dimensions-overground space, ground environment and underground space. Adhere to comprehensive development of the 
vertical stratification, transverse spatial connected to each other, the surface buildings and underground engineering coordination, ensuring urban space as a whole and coordinated development. Pay attention to coordinated development both overground space and underground spcae,first to satisfy the basic function of the underground space, encourage mixed development, comprehensive utilization, improve utility rate of space. Protect and improve the ecological environment of the city, scientifically forecast the needs of urban development.Insist to adjust measures to local conditions, with due attention to both short and long-range targets, comprehensive planning, implement by step. Make the development of underground space can adapt with the development level of national and local economics and technologies.

\section{Planning Contents of Development and Utilization of Urban Underground Space}

\section{Overall layout of underground space planning}

According to the master urban planning, the structure of the underground space layout should be based on the functional structure of "two zones and three groups", and effectively combined with the overground space, so that it will form a "group type" spatial structure. Up to the end of planning, a structure of "two belts, three cores, seven areas, and multiple nodes" will be formed, as shown in Fig.1.

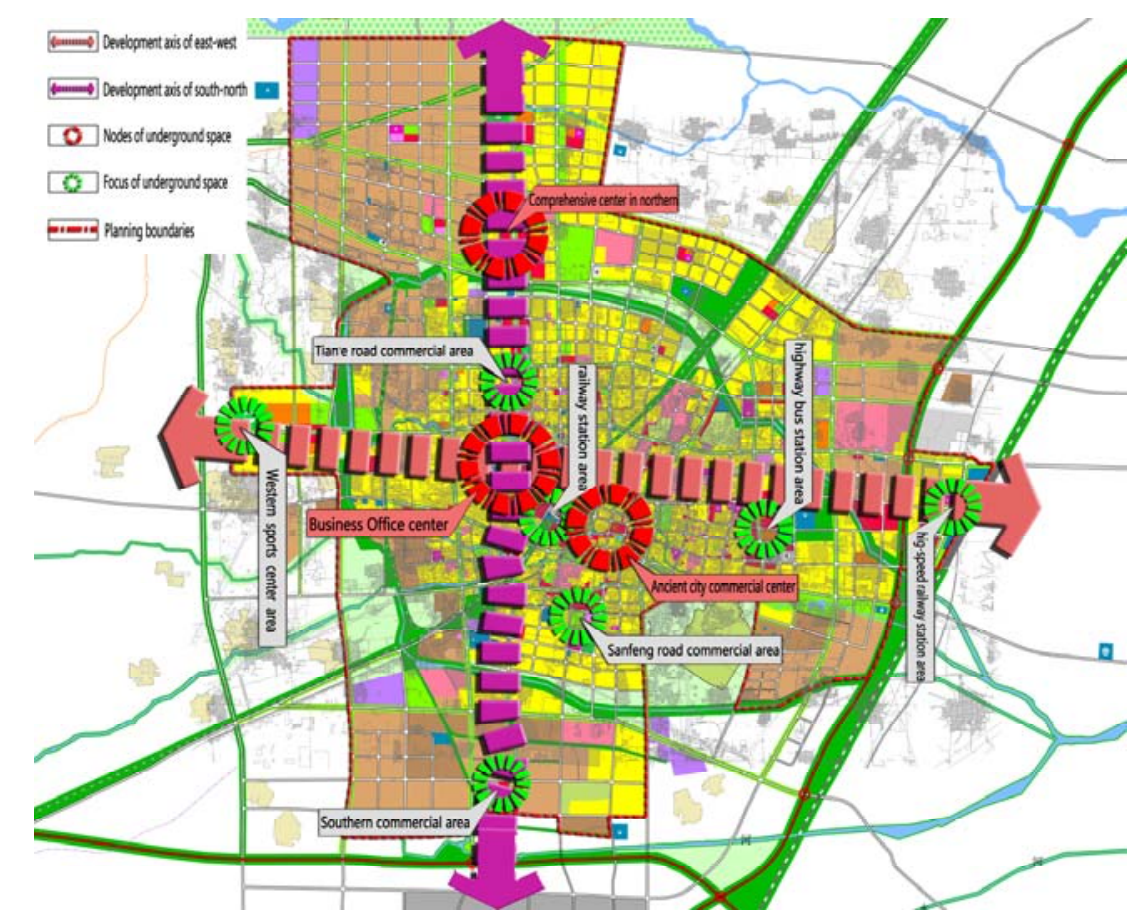

Fig. 1 The overall structure of underground space in Baoding

Two belts: long the Chaoyang Road and Dongfeng Road (north to Qiyi Road, South to the Dongfeng Road) formed the development of underground space.

Three cores: three municipal comprehensive centers as don't the centers of development and utilization of underground space. They refers to the historical and cultural commercial center; Integrated CBD at the intersection of Chaoyang Street and Dongfeng Road; Integrated center at the north to the North Second Ring and both sides of Chaoyang North Street. "Two belts" is the core of the development and utilization of urban underground space.

Seven areas: gym areas on both sides of the Qiyi Road; the high-end business exhibitions and knowledge-based economic centers around high-speed railway; region at Chaoyang Street and the Swan Road intersection; region to the East of Chaoyang Street, and south to the special railway line; region to the south of Sanfengzhongg Road, west of the Yonghua Street; region on both sides of the East Second Ring Road, Dongfeng Road and Yuhua Road; railway station area.

Multi point: nodes of single project of exploration of underground space. 


\section{Underground space special planning}

(1)Underground transport system planning

Starting from the solution of urban traffic problems and the actual demand, put forward specific plannings ,aimed at projects such as underground parking facilities system, underground pedestrian system and underground transportation facilities. During the planning,consrtuct 11 public underground motor vehicle parking lots which located in the south side of Zhi Li Zong Du Fu square, sports center, high speed railway station, botanical gardens and other areas; build Yuhua Road underground civil air defense construction, which function is given priority to with business and pedestrian traffic, string around underground public space, form an organic whole; the subway lines will be used in the form of the ring and radial in prospect.

(2) Underground municipal facilities system planning

Insists combination of distance, the principle of moderate advance, consider phased implementation. Recently in order to integrate and standardize the status of the underground municipal facilities system, improve the urban underground pipeline comprehensive supporting project. Full and reasonable utilizate of underground space resources in long term, plan to put gasification storage station and the heat exchange station municipal station facilities underground, saving floor space resources. At the same time to meet the needs of urban development, put forward the programming of the underground comprehensive utility tunnel in future.

(3)Underground disaster prevention system planning

Urban civil air defense projects should be in accordance with the civil air defense special planning during the planning period. Establish a protection protective space system which is connected well, reliable protected, stems and branches communicated with the civil defense engineering as the main body, convenient and quick evacuation passageway as the link. The underground space should be an important storage space of disaster prevention and mitigation, evacuation and the aid of traffic space. (4)Underground space and conservation planning

Baoding is a national historical and cultural city announced by the State Department in 1986. Therefore, historical and cultural resources should be strictly protected in the development and utilization of underground space. It is also appropriate to encourage the utilization of underground space to supplement and improve the function of historical and cultural protection zone. Such as Zong Du Shu district, the development of underground space is needed to supplement and perfect the commercial function, In order to better protect the surficial building style,

The key area of underground space development and utilization(as shown in Fig.2)

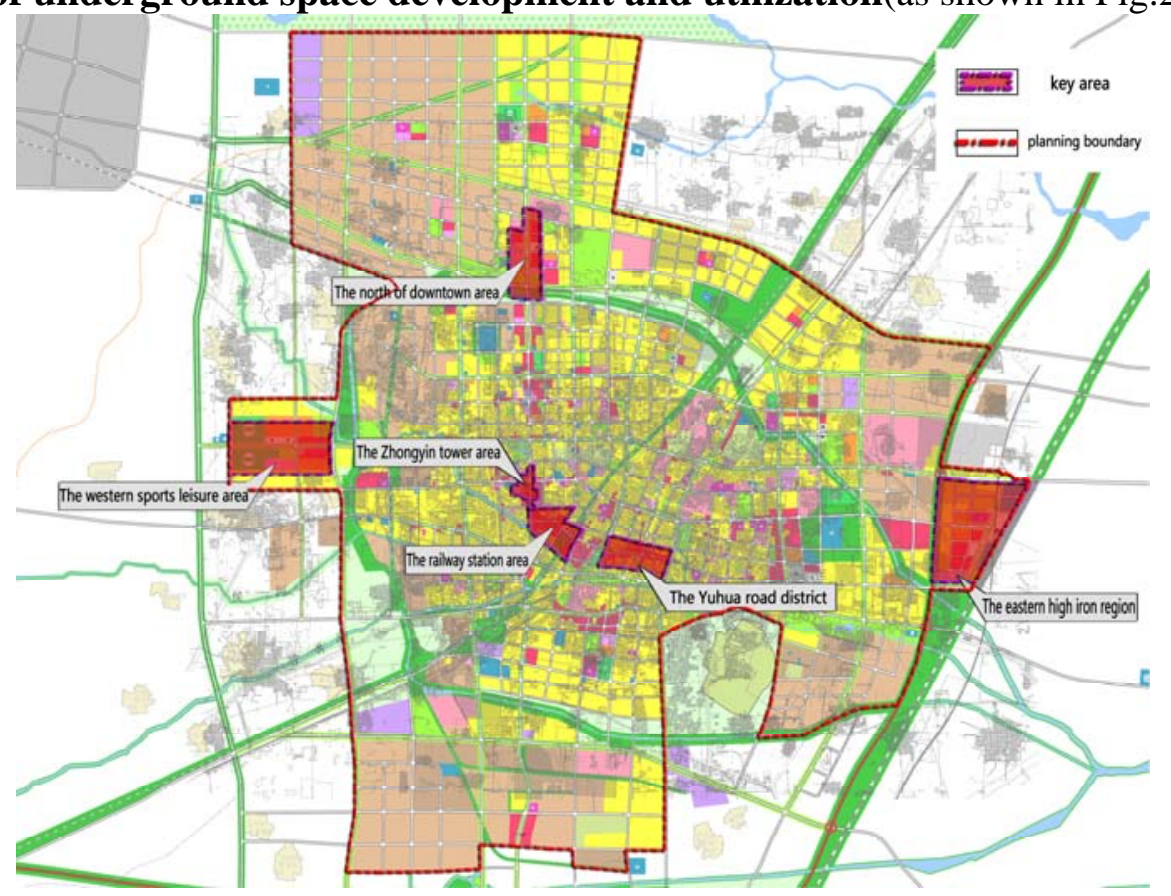

Fig. 2 The key area of underground space in Baoding 
(1)The Zhongyin tower area

This area is the present situation of municipal comprehensive district, mainly to undertake administrative, business functions. Carrying on overall layout with the "underground commercial, underground parking and traffic distribution and other" comprehensive function model, formatting of large underground complex in future prospect by combined with the subway site connected integration.

(2)The Yuhua road district

This area is the core section of this historic and cultural city. Planning with profound historical and cultural heritage as the foundation, with good business conditions for the protection, to shape this area as the historical style and features themed "Baoding ancient image demonstration district".

(3)The western sports leisure area

It is an important part of the construction of cultural Baoding City, also the future region of the city's sports function and its highly concentrated areas. Function is given priority to with business services and relieving traffic. In accordance with the "underground commercial, underground parking and traffic distribution and other" model to carry on the overall layout. Reserve the location for the subway line and the site and prepare well connectivity measures, to form the underground complex in future prospect.

(4)The eastern High iron region

High-speed railway passenger transport station is a railway passenger transport hub, which has comprehensive transfer function of railway passenger transport, bus, taxi, subway (reserved channel). Therefore, the main task of underground space planning is to shunt the traffic flow quickly and shorten the transfer distance. Planning area of the underground space in accordance with the " underground commercial, underground parking and traffic distribution and other " mode of overall layout, so that the commercial space and transport space to communicate with the overground, the formation of organic unity.

(5)The north of downtown area

It is the urban commercial finance and educational scientific research area in the future. Main area function is "commercial + traffic", the development and utilization of underground space is given priority to with traffic and meeting the demand of related functions.

(6)The railway station area

Planning area is one of the important city transport hub, is also a commercial finance and highly concentrated area of the foreign land for traffic and its activities.

\section{Conclusion}

In large and medium-sized cities, underground space planning should establish a closely linking with actual development demand, urban overall planning and regulatory planning. After communication with land department, construction department and other important organizations, the final detailed plan should be feasible, above all, to put forward a series of specific construction projects and construction sequence which contribute to plan implementation. Besides, underground space development requires great investment, to solve this problem, supporting policy measures should be established, also social capital should be introduced.

\section{References}

[1] Yang Chen, Planners. Vol. 27 (2011), p. 48-52. In Chinese.

[2] Qiaoyi He, Gengyang Cai, Planners. Vol. 30 (2014), p. 42-47. In Chinese.

[3] Yu Shu, Kun Liu, Meiliang Zhang,Planners. Vol. 23 (2007), p. 5-8. In Chinese.

[4] The master plan of the development and utilization of underground space in Baoding City (2009-2020). Urban and Rural Planning and Design Institute of Baoding City. In Chinese. 